\title{
Biochemical genetics of a natural population of Escherichia coli: seasonal changes in alleles and haplotypes
}

\author{
Gulietta M. Pupot and Barry J. Richardson
}

School of Science, University of Western Sydney, Hawkesbury, Richmond NSW 2753, Australia
Author for correspondence: Barry J. Richardson. Fax: +6145701 621. e-mail: b.richardson@uws.edu.au

The level of diversity, degree of enzyme polymorphism, effective population size, and the relative roles of drift and selection were examined in a crosssection of a natural Escherichia coli population based on random samples of haplotypes of $E$. coli isolated from sewage. The population studied contained $E$. coli strains derived from a human population of approximately 16000 individuals, as well as from other sources. Three sample sets were taken between May and August. Each set consisted of 100 E. coli clones. Six enzyme loci [GPI (5 alleles), GPD (5 alleles), PGD (10 alleles), ADH (8 alleles), IDH (6 alleles), PGM (6 alleles)] were surveyed electrophoretically for each clone; 159 different haplotypes were obtained and it is likely that all possible combinations are present in the population sampled. The large numbers of different haplotypes observed were distributed as a series of four genetically similar families of clones. The large estimated effective population size $\left(N_{e}=10^{10}\right)$ means that the observed large and highly significant changes in allele frequencies with time are not due to genetic drift. Selection, though not necessarily at the loci studied, is considered the only likely explanation.

Keywords: Escherichia coli, population genetics, electrophoresis, quasi-species, allozymes

\section{INTRODUCTION}

Milkman (1972) designated Escherichia coli as the ideal organism to address the neutralist/selectionist controversy. Since then studies have attempted to define the level of polymorphism, degree of genetic diversity in natural populations of $E$. coli and their significance to the selectionist/neutralist controversy (Milkman, 1973; Selander \& Levin, 1980; Selander et al., 1986; Helling et al., 1987; Sawyer et al., 1987; Dykhuizen \& Dean, 1990). These studies, however, have been of limited value and the interpretation of their results is ambiguous as $E$. coli populations from individual humans (or from animals associated with humans) were used, often taken nonrandomly from ill or hospitalized individuals. Longitudinal studies dealing with enzyme variation in a natural E. coli population in a large host population have never been carried out.

†Present address: Department of Microbiology, University of Sydney, Sydney, NSW, Australia.

Abbreviations: $A D H$, alcohol dehydrogenase; GPD, glucose-6-phosphate dehydrogenase; GPI, glucose-6-phosphate isomerase; IDH, isocitrate dehydrogenase; PGD, 6-phosphogluconate dehydrogenase; PGM, phosphoglucomutase.
The purpose of this study was to elucidate the level of genetic diversity and variability in an Australian natural population of E. coli and to follow changes in allele and haplotype frequencies with time. The study was carried out with the following objectives: (1) to determine the amount of genetic diversity in natural populations of $E$. coli in Australia; (2) to determine if isolates of $E$. coli obtained from sewage exhibit allelic linkage disequilibrium; (3) to determine the effects of time on allele frequencies and on haplotype frequencies; and (4) to consider these findings in the light of the neutralist/ selectionist debate.

\section{METHODS}

Isolation of $\boldsymbol{E}$. coli. Untreated sewage effluent was sampled directly as it entered the Richmond Sewage Treatment Plant, Richmond, New South Wales (Lat. $37^{\circ} 35^{\prime} \mathrm{S}$ Long. $150^{\circ} 50^{\prime} \mathrm{E}$ ). This plant services a human population of approximately 16000 individuals and their associated environment. At each sampling time, a composite sample was obtained from five sub-samples taken at 2 min intervals. Three samples were collected at the following times: set 1, 4 May 1992; mid-autumn; set 2, 3 July 1992; mid-winter; set 3, 24 August 1992; late winter. On the last occasion two sample sets were taken $1 \mathrm{~h}$ apart (sets $3 \mathrm{~A}$ and $3 \mathrm{~B}$ ). One hundred randomly chosen $E$. coli clones were isolated on each day and stored as live cultures at $-80^{\circ} \mathrm{C}$. 
Electrophoresis. Lysates of each clone were prepared by sonication. High voltage zone electrophoresis employing $10 \times 17 \mathrm{~cm}$ cellulose acetate gels (Cellogel, Chematron) was used to detect allelic variation at a series of enzyme loci. Electrophoretic methods were carried out as described by Richardson et al. (1986). The optimal electrophoretic conditions for each locus were as follows. Glucose-6-phosphate dehydrogenase (GPD, EC 1.1.1.49), alcohol dehydrogenase (ADH, EC 1.1.1.1), 6-phosphogluconate dehydrogenase (PGD, EC 1.1.1.44) and glucose-6-phosphate isomerase (GPI, EC 5.3.1.9) were run using 0.046 M Tris/barbitone, $\mathrm{pH} 8.8$, buffer system. Isocitrate dehydrogenase (IDH, EC 1.1.1.42) and phosphoglucomutase (PGM, EC 5.4.2.2) were run using $0.015 \mathrm{M}$ Tris $/ 0.05 \mathrm{M}$ EDTA/borate with $0.01 \mathrm{M} \mathrm{MgCl}_{2}$, $\mathrm{pH} 7 \cdot 8$.

Scoring of gels. The mobilities of enzymes from different isolates were compared on the same gel sheet. The absence of enzyme activity was scored as a null phenotype if other enzymes in the same lysate had normal levels of activity.

\section{RESULTS}

\section{Genetic diversity between alleles}

The distribution of phenotypes between sample sets is summarized in Table 1. Estimates of allelic diversity were calculated from the frequencies of alleles according to Nei (1975). Genetic diversity ranged from $0 \cdot 20$ for the least polymorphic locus, GPD, to 0.89 for the most polymorphic locus, PGD. The mean diversity per locus was 0.61 , which is $20 \%$ greater than the value of 0.47 reported by Selander \& Levin (1980) for 20 enzyme loci assayed in 109 clones of $E$. coli from a restricted number of individual human hosts. A comparison of genetic diversity across all three sample sets showed very little variation, with values of 0.60 for set $1,0.64$ for set 2 and 0.58 for set 3 .

\section{Effective population size}

The effective population size and, hence, the inbreeding coefficient was calculated according to Maynard Smith (1991). The effective population size of E. coli was found to be $1.24 \times 10^{10}$. Though very large, this estimate of effective population size of $E$. coli populations is many orders of magnitude less than the actual size of the population. The actual number of $E$. coli cells in the world is enormous, perhaps $10^{20}$ (Levin, 1981), and the effective population size represents a small fraction of the actual size. This is attributed to the alternation of circumstances under which $E$. coli strains grow rapidly with those where the same strain may become very rare or extinct. In such cases, the effective population size would be much smaller than the actual size (Nei \& Grauer, 1984).

The calculated value of $F$ (the repeated occurrence of the same all-locus phenotype) was 0.002 , which is lower than the value of 0.06 given by Caugant et al. (1987). According to Maynard Smith (1991), the value of $F$ for the whole species of E. coli probably lies in the range $0 \cdot 01-0 \cdot 001$. The value of 0.002 estimated in this study indicates that a greater proportion of the E. coli population was assessed in this study than in previous studies. It is anticipated that sampling a greater range of the world $E$. coli population would further lower the value of $F$.

\section{Sampling effects}

Before interpreting the differences observed between sampling dates (see below), it is essential to test for variation due to experimental technique. Consequently, set 3 was collected as two sample sets (A and B) obtained $1 \mathrm{~h}$ apart (Table 2). A $\chi^{2}$ homogeneity test was used to determine if allele frequencies at each locus varied significantly between the two sampling times. The tests

\section{Table 1. Summary of phenotypes observed at each locus in each sample set}

Electrophoretic types are given in the order from slowest to fastest. There is no equivalence between mobilities of different loci.

Homogeneity $\left(\chi^{2}\right)$ tests were carried out using the two common alleles plus the remaining alleles combined and assuming each locus is independently distributed (see text). The three commonest alleles were kept separate for PGD. ** $0 \cdot 001<P<0 \cdot 0001$; *** $P<0 \cdot 0001$.

\begin{tabular}{|c|c|c|c|c|c|c|c|c|c|c|c|c|c|c|c|c|c|c|c|}
\hline \multirow[t]{2}{*}{ Mobility } & \multirow[b]{2}{*}{ Set... } & \multicolumn{3}{|c|}{ GPD } & \multicolumn{3}{|c|}{ GPI } & \multicolumn{3}{|c|}{ IDH } & \multicolumn{3}{|c|}{$\mathbf{A D H}$} & \multicolumn{3}{|c|}{ PGM } & \multicolumn{3}{|c|}{ PGD } \\
\hline & & 1 & 2 & 3 & 1 & 2 & 3 & 1 & 2 & 2 & 1 & 2 & 3 & 1 & 2 & 3 & 1 & 2 & 3 \\
\hline Null & & 0 & 2 & 0 & - & - & - & - & - & - & 6 & 12 & 12 & 0 & 7 & 0 & 7 & 0 & 3 \\
\hline 1 & & 10 & 3 & 3 & 1 & 4 & 0 & 4 & 4 & 8 & 0 & 5 & 0 & 8 & 18 & 7 & 0 & 3 & 2 \\
\hline 2 & & 85 & 80 & 92 & 41 & 52 & 5 & 1 & 0 & 2 & 0 & 0 & 1 & 1 & 5 & 4 & 9 & 18 & 6 \\
\hline 3 & & - & - & - & 10 & 3 & 36 & 66 & 67 & 36 & 68 & 50 & 30 & 89 & 69 & 88 & 0 & 7 & 0 \\
\hline 4 & & 1 & 0 & 1 & 46 & 40 & 58 & 0 & 1 & 0 & 0 & 1 & 0 & 0 & 5 & 0 & 37 & 62 & 45 \\
\hline 5 & & 4 & 15 & 4 & 2 & 1 & 1 & 11 & 28 & 51 & 26 & 25 & 55 & 2 & 2 & 1 & 0 & 4 & 14 \\
\hline 6 & & - & - & - & - & - & - & 18 & 0 & 3 & 0 & 2 & 1 & - & - & - & 26 & 6 & 13 \\
\hline 7 & & - & - & - & - & - & - & - & - & - & 0 & 5 & 1 & - & - & - & 3 & 0 & 5 \\
\hline 8 & & - & - & - & - & - & - & - & - & - & - & - & - & - & - & - & 3 & 0 & 0 \\
\hline \multirow[t]{2}{*}{9} & & - & - & - & - & - & - & - & - & - & - & - & - & - & - & - & 15 & 0 & 2 \\
\hline & & \multicolumn{3}{|c|}{$\chi_{4}^{2}=15 \cdot 7^{* *}$} & \multicolumn{3}{|c|}{$\chi_{4}^{2}=65 \cdot 4 * * *$} & \multicolumn{3}{|c|}{$\chi_{4}^{2}=49 \cdot 8^{* * *}$} & \multicolumn{3}{|c|}{$\chi_{4}^{2}=42 \cdot 9 * * *$} & \multicolumn{3}{|c|}{$\chi_{4}^{2}=17 \cdot 82^{* *}$} & \multicolumn{3}{|c|}{$\chi_{6}^{2}=37 \cdot 2^{* * *}$} \\
\hline
\end{tabular}


Table 2. Summary of phenotypes observed at each locus in sample sets $3 A$ and $3 B$ collected $1 \mathrm{~h}$ apart on the same day

Electrophoretic numbering and $\chi^{2}$ tests are the same as in Table 1.

\begin{tabular}{|c|c|c|c|c|c|c|c|c|c|c|c|c|c|}
\hline \multirow[t]{2}{*}{ Mobility } & \multirow[b]{2}{*}{ Set... } & \multicolumn{2}{|c|}{ GPD } & \multicolumn{2}{|c|}{ GPI } & \multicolumn{2}{|c|}{ IDH } & \multicolumn{2}{|c|}{ ADH } & \multicolumn{2}{|c|}{ PGM } & \multicolumn{2}{|c|}{ PGD } \\
\hline & & $3 A$ & 3B & $3 \mathbf{A}$ & 3B & $3 \mathbf{A}$ & 3B & $3 A$ & 3B & $3 \mathbf{A}$ & 3B & $3 \mathbf{A}$ & 3B \\
\hline Null & & 3 & 0 & - & - & - & - & 3 & 9 & - & - & 2 & 1 \\
\hline 1 & & 45 & 47 & 4 & 1 & 7 & 1 & - & - & 4 & 3 & 2 & 0 \\
\hline 2 & & 1 & 0 & 17 & 19 & 0 & 2 & 0 & 1 & 1 & 3 & - & - \\
\hline 3 & & 1 & 3 & 28 & 30 & 19 & 17 & 17 & 13 & 44 & 44 & - & - \\
\hline 4 & & & & 1 & 0 & - & - & - & - & - & - & 20 & 25 \\
\hline 5 & & & & & & 22 & 29 & 29 & 26 & 1 & 0 & 8 & 6 \\
\hline 6 & & & & & & 2 & 1 & 0 & 1 & & & 7 & 6 \\
\hline 7 & & & & & & & & 1 & 0 & & & 3 & 2 \\
\hline 8 & & & & & & & & & & & & - & - \\
\hline 9 & & & & & & & & & & & & 1 & 1 \\
\hline$\chi^{2}$ & & \multicolumn{2}{|c|}{0.54} & \multicolumn{2}{|c|}{$0 \cdot 16$} & \multicolumn{2}{|c|}{$1 \cdot 73$} & \multicolumn{2}{|c|}{$0 \cdot 28$} & \multicolumn{2}{|c|}{0} & \multicolumn{2}{|c|}{1.06} \\
\hline
\end{tabular}

showed no sigificant differences at any locus, and consequently any significant differences between sets 1, 2 and 3 are unlikely to be due to sampling effects and can be ascribed to seasonal changes.

\section{Seasonal effects on allele frequencies}

The $\mathrm{pH}$ of the sewage ranged from 8.45 to 8.64 and temperature from $17 \cdot 0$ to $17 \cdot 5^{\circ} \mathrm{C}$. There was no seasonal pattern in the variation. The samples were collected at approximately the same time of the day on a working day after several days without rain. No events that would have brought large numbers of non-residents to the area occurred at the times of sampling.

Analysis of the allele frequencies given in Table 1 showed that there were highly significant differences due to changes in frequency of alleles over time.

\section{Actual and effective number of clones}

The comparison of the electromorph profiles across all isolates in sample sets $1,2,3 \mathrm{~A}$ and $3 \mathrm{~B}$ revealed $64,62,32$ and 32 haplotypes respectively (Table 3 ). The total number in combined set 3 (set $3 \mathrm{~A}$ plus $3 \mathrm{~B}$ ) was 55 . The differences in the number of haplotypes observed between sets can be ascribed to sampling effects. A total of 159 different haplotypes was obtained during the project.

\section{Temporal variation in haplotype frequencies}

The frequency of each haplotype was determined for each of the sample sets (Table 3). An examination of the relative frequencies showed great variation in the frequency of haplotypes: no haplotype dominated set 1 (maximum $4 \%$ ), one haplotype reached a frequency of $12 \%$ in set 2 , while a different haplotype reached a frequency of $28 \%$ in set 3 . Indistinguishable distributions of haplotypes were found in sets $3 \mathrm{~A}$ and $3 \mathrm{~B}$.

Comparison of the electromorph profiles of set 2 and set 3 revealed only two haplotypes in common between the two sets. Only one haplotype was observed over the entire study period from May to August, with an overall total frequency of $0 \cdot 1$.

Examination of the results showed, however, that each sample set consisted of a restricted number of families of clones varying by changes at one or two loci. This observation is similar to that reported by other workers, who described these clusters of similar forms as strains (Selander \& Musser, 1990), hierarchies (Milkman \& Bridges, 1990) or quasi-species (Eigen et al., 1988). The sample sets studied here contain four families of haplotypes, where a family consists of a haplotype plus single or double change variants from this haplotype. The 'parent' haplotype, i.e. the combination of the most frequent alleles in the family, is shown for each family in Table 4. Nearly $90 \%$ of the haplotypes in each set can be ascribed to one of these four families (Table 5). While the frequency of families did not change between sets 1 and 2 , the frequency of family $B$ increased while family A decreased significantly between sets 2 and 3 (Table 5). The rarer family $C$ may also be diminishing in frequency with time.

Examination of the data for parallel changes in frequencies of common alleles between families shows no consistent pattern. In some cases changes were in parallel, for example the sudden increase in the $G P D^{4}$ allele in the A, $B$ and $C$ families in set 2 , while in other cases changes in frequency occurred in some but not all families, for example the drop in $P G D^{4}$ frequency in families $\mathrm{A}, \mathrm{C}$ and $\mathrm{D}$ but not $\mathrm{B}$ in set 3 . 
Table 3. Phenotype and percentage frequency of each haplotype in the three sample sets

\begin{tabular}{|c|c|c|c|c|c|c|c|c|c|c|c|c|c|c|c|}
\hline \multirow[t]{2}{*}{ Haplotype } & \multicolumn{6}{|c|}{ Locus } & \multirow{2}{*}{$\begin{array}{c}\text { Frequency } \\
(\%)\end{array}$} & \multirow[t]{2}{*}{ Haplotype } & \multicolumn{6}{|c|}{ Locus } & \multirow{2}{*}{$\begin{array}{c}\text { Frequency } \\
(\%)\end{array}$} \\
\hline & GPI & ADH & GPD & PGD & IDH & PGM & & & GPI & $\mathbf{A D H}$ & GPD & PGD & IDH & PGM & \\
\hline \multicolumn{8}{|c|}{ Sample set 1} & \multicolumn{7}{|c|}{ Sample set 1 (cont.) } & \\
\hline 1 & 2 & 5 & 2 & 6 & 3 & 3 & 1 & 54 & 4 & 3 & 2 & 6 & 3 & 1 & 1 \\
\hline 2 & 2 & 5 & 2 & 2 & 3 & 3 & 1 & 55 & 2 & 3 & 2 & 6 & 1 & 3 & 1 \\
\hline 3 & 2 & 3 & 2 & 6 & 3 & 3 & 3 & 56 & 4 & $\mathbf{N}$ & 2 & 4 & 3 & 3 & 1 \\
\hline 4 & 2 & 3 & 2 & 8 & 6 & 3 & 1 & 57 & 4 & 3 & 2 & 6 & 3 & 3 & 3 \\
\hline 5 & 2 & 3 & 2 & 9 & 6 & 3 & 4 & 58 & 4 & 5 & 2 & 4 & 2 & 1 & 1 \\
\hline 6 & 4 & 5 & 4 & 4 & 3 & 3 & 2 & 59 & 4 & 5 & 2 & 6 & 3 & 1 & 2 \\
\hline 7 & 2 & 3 & 1 & 4 & 5 & 1 & 1 & 60 & 4 & 5 & 2 & 6 & 3 & 5 & 1 \\
\hline 8 & 4 & 5 & 2 & 4 & 3 & 5 & 1 & 61 & 4 & 5 & 2 & 4 & 3 & 1 & 1 \\
\hline 9 & 4 & 3 & 2 & 2 & 5 & 3 & 1 & 62 & 4 & 5 & 2 & 6 & 3 & 2 & 1 \\
\hline 10 & 4 & 5 & 4 & 9 & 6 & 3 & 1 & 63 & 3 & 3 & 2 & 2 & 3 & 3 & 1 \\
\hline 11 & 4 & 5 & 2 & 4 & 3 & 3 & 2 & 64 & 4 & 5 & 2 & $\mathrm{~N}$ & 3 & 3 & 1 \\
\hline 12 & 4 & 5 & 2 & $\mathrm{~N}$ & 5 & 3 & 2 & & & & & & & & \\
\hline 13 & 4 & 3 & 4 & 9 & 3 & 3 & 1 & \multicolumn{7}{|c|}{ Sample set 2} & \\
\hline 14 & 2 & 3 & 2 & 4 & 3 & 3 & 7 & 1 & 4 & 3 & 2 & 6 & 3 & 3 & 1 \\
\hline 15 & 4 & 5 & 2 & 4 & 5 & 3 & 1 & 2 & 4 & 5 & 2 & 2 & 1 & 3 & 1 \\
\hline 16 & 3 & 3 & 2 & $\mathrm{~N}$ & 3 & 3 & 2 & 3 & 2 & 3 & 2 & 6 & 3 & 3 & 3 \\
\hline 17 & 4 & 5 & 2 & 9 & 5 & 3 & 3 & 4 & 2 & 3 & 2 & 6 & 1 & 3 & 1 \\
\hline 18 & 3 & 3 & 2 & 4 & 3 & 3 & 2 & 5 & 2 & 5 & 2 & 4 & 1 & 3 & 1 \\
\hline 19 & 3 & 3 & 2 & 4 & 6 & 3 & 1 & 6 & 4 & 6 & 4 & 4 & 4 & 3 & 1 \\
\hline 20 & 2 & 3 & 2 & 2 & 3 & 3 & 4 & 7 & 2 & 3 & 2 & 5 & 3 & 3 & 2 \\
\hline 21 & 2 & 3 & 2 & 8 & 6 & 3 & 1 & 8 & 2 & 5 & 2 & 4 & 3 & 3 & 5 \\
\hline 22 & 4 & 3 & 2 & 9 & 3 & 3 & 2 & 9 & 4 & 6 & 4 & 5 & 3 & 3 & 1 \\
\hline 23 & 3 & 3 & 2 & 8 & 3 & 3 & 1 & 10 & 4 & $\mathrm{~N}$ & 1 & 3 & 1 & 2 & 1 \\
\hline 24 & 2 & 3 & 2 & 4 & 6 & 3 & 2 & 11 & 4 & $\mathrm{~N}$ & 4 & 4 & 3 & 1 & 2 \\
\hline 25 & 2 & 3 & 2 & 9 & 3 & 3 & 2 & 12 & 2 & 3 & 2 & 2 & 3 & 3 & 5 \\
\hline 26 & 2 & 3 & 2 & $\mathrm{~N}$ & 3 & 3 & 1 & 13 & 4 & 5 & 2 & 3 & 5 & 3 & 1 \\
\hline 27 & 1 & 3 & 2 & 9 & 3 & 3 & 1 & 14 & 2 & 3 & 2 & 4 & 3 & 3 & 12 \\
\hline 28 & 2 & 3 & 1 & 9 & 3 & 3 & 1 & 15 & 4 & 5 & 4 & 4 & 3 & 3 & 1 \\
\hline 29 & 4 & 5 & 2 & 6 & 3 & 3 & 1 & 16 & 2 & 3 & $\mathrm{~N}$ & 2 & 3 & 3 & 1 \\
\hline 30 & 4 & 3 & 2 & 4 & 3 & 3 & 3 & 17 & 4 & $\mathrm{~N}$ & $\mathrm{~N}$ & 4 & 5 & 1 & 1 \\
\hline 31 & 3 & 5 & 2 & 6 & 3 & 3 & 1 & 18 & 2 & 3 & 2 & 4 & 5 & 3 & 1 \\
\hline 32 & 4 & 3 & 2 & 7 & 6 & 3 & 1 & 19 & 4 & $\mathbf{N}$ & 4 & 4 & 5 & 1 & 2 \\
\hline 33 & 2 & 3 & 1 & 4 & 3 & 3 & 4 & 20 & 4 & 5 & 2 & 4 & 3 & 2 & 1 \\
\hline 34 & 4 & 5 & 2 & 6 & 6 & 3 & 1 & 21 & 2 & 3 & 4 & 4 & 3 & 3 & 3 \\
\hline 35 & 4 & $\mathrm{~N}$ & 2 & 6 & 3 & 3 & 2 & 22 & 4 & 5 & 2 & 1 & 3 & 3 & 1 \\
\hline 36 & 4 & 3 & 1 & 6 & 3 & 3 & 1 & 23 & 2 & 1 & 2 & 6 & 3 & 3 & 1 \\
\hline 37 & 4 & $\mathrm{~N}$ & 2 & 6 & 6 & 3 & 1 & 24 & 4 & 5 & 4 & 5 & 5 & 1 & 1 \\
\hline 38 & 2 & 3 & 2 & 6 & 6 & 3 & 3 & 25 & 3 & $\mathrm{~N}$ & 2 & 4 & 3 & 3 & 1 \\
\hline 39 & 4 & 3 & 2 & 6 & 1 & 3 & 1 & 26 & 4 & 5 & 2 & 3 & 5 & 2 & 1 \\
\hline 40 & 5 & 3 & 2 & 4 & 3 & 3 & 2 & 27 & 4 & 7 & 1 & 2 & 3 & 2 & 1 \\
\hline 41 & 2 & 3 & 2 & 4 & 5 & 3 & 1 & 28 & 3 & $\mathrm{~N}$ & 2 & 2 & 5 & $\mathrm{~N}$ & 1 \\
\hline 42 & 2 & 3 & 1 & 6 & 6 & 3 & 1 & 29 & 3 & 5 & 2 & 4 & 5 & 1 & 1 \\
\hline 43 & 4 & 3 & 2 & 7 & 1 & 3 & 1 & 30 & 2 & 3 & 2 & 4 & 3 & 2 & 1 \\
\hline 44 & 4 & 3 & 1 & 4 & 3 & 3 & 1 & 31 & 2 & 3 & 2 & 1 & 3 & 3 & 1 \\
\hline 45 & 2 & 3 & 2 & 7 & 3 & 3 & 1 & 32 & 4 & $\mathrm{~N}$ & 4 & 4 & 5 & 3 & 2 \\
\hline 46 & 4 & $\mathrm{~N}$ & 2 & 2 & 3 & 3 & 1 & 33 & 2 & 1 & 2 & 2 & 3 & 1 & 1 \\
\hline 47 & 3 & 3 & 2 & 4 & 3 & 1 & 1 & 34 & 2 & 5 & 2 & 4 & 3 & 4 & 1 \\
\hline 48 & 2 & 3 & 2 & 6 & 6 & 1 & 1 & 35 & 4 & 3 & 2 & 4 & 3 & 3 & 3 \\
\hline 49 & 4 & 5 & 1 & $\mathrm{~N}$ & 5 & 3 & 1 & 36 & 2 & 3 & 2 & 4 & 3 & 1 & 1 \\
\hline 50 & 4 & $\mathrm{~N}$ & 2 & 4 & 5 & 3 & 1 & 37 & 2 & 3 & 2 & 4 & 3 & 4 & 1 \\
\hline 51 & 3 & 5 & 2 & 4 & 3 & 3 & 1 & 38 & 4 & 7 & 2 & 2 & 5 & 3 & 1 \\
\hline 52 & 4 & 3 & 2 & 4 & 1 & 3 & 1 & 39 & 2 & 3 & 2 & 2 & 3 & 1 & 1 \\
\hline 53 & 4 & 3 & 3 & 2 & 3 & 3 & 1 & 40 & 2 & 5 & 1 & 4 & 3 & 3 & 1 \\
\hline
\end{tabular}


Table 3. (cont.)

\begin{tabular}{|c|c|c|c|c|c|c|c|c|c|c|c|c|c|c|c|}
\hline \multirow[t]{2}{*}{ Haplotype } & \multicolumn{6}{|c|}{ Locus } & \multirow{2}{*}{$\begin{array}{l}\text { Frequency } \\
\qquad(\%)\end{array}$} & \multirow[t]{2}{*}{ Haplotype } & \multicolumn{6}{|c|}{ Locus } & \multirow{2}{*}{$\begin{array}{c}\text { Frequency } \\
\qquad(\%)\end{array}$} \\
\hline & GPI & ADH & GPD & PGD & IDH & PGM & & & GPI & ADH & GPD & PGD & IDH & PGM & \\
\hline \multicolumn{8}{|c|}{ Sample set 2 (cont.) } & \multicolumn{7}{|c|}{ Sample set 3 (cont.) } & \\
\hline 41 & 4 & 7 & 4 & 4 & 5 & 3 & 1 & 16 & 4 & 5 & 2 & 4 & 5 & 5 & 1 \\
\hline 42 & 4 & 7 & 2 & 4 & 5 & 3 & 2 & 17 & 2 & 3 & 2 & 9 & 6 & 3 & 1 \\
\hline 43 & 2 & 1 & 2 & 4 & 3 & 3 & 2 & 18 & 3 & 3 & 1 & 5 & 3 & 3 & 1 \\
\hline 44 & 5 & $\mathrm{~N}$ & 2 & 2 & 3 & 1 & 1 & 19 & 5 & 3 & 2 & 6 & 3 & 3 & 2 \\
\hline 45 & 4 & 5 & 2 & 4 & 5 & 1 & 2 & 20 & 3 & 3 & 2 & 2 & 3 & 3 & 2 \\
\hline 46 & 2 & 3 & 2 & 2 & 3 & 4 & 2 & 21 & 4 & 7 & 2 & 5 & 5 & 3 & 1 \\
\hline 47 & 1 & 3 & 2 & 4 & 3 & 1 & 2 & 22 & 3 & 5 & 2 & 7 & 3 & 3 & 1 \\
\hline 48 & 4 & 5 & 2 & 4 & 5 & 3 & 3 & 23 & 3 & 5 & 2 & 5 & 3 & 3 & 2 \\
\hline 49 & 4 & 5 & 2 & 2 & 5 & 3 & 1 & 24 & 4 & $\mathrm{~N}$ & 4 & 7 & 1 & 1 & 1 \\
\hline 50 & 2 & 3 & 2 & 3 & 3 & 3 & 2 & 25 & 4 & 5 & 2 & $\mathrm{~N}$ & 1 & 3 & 1 \\
\hline 51 & 2 & 3 & 2 & 3 & 3 & 1 & 1 & 26 & 4 & 5 & 2 & 3 & 1 & 3 & 1 \\
\hline 52 & 4 & 3 & 2 & 4 & 5 & 3 & 1 & 27 & 4 & $\mathrm{~N}$ & 2 & 1 & 3 & 3 & 1 \\
\hline 53 & 4 & 3 & 2 & 4 & 5 & 1 & 1 & 28 & 4 & $\mathrm{~N}$ & 3 & 4 & 1 & 1 & 1 \\
\hline 54 & 4 & 3 & 2 & 2 & 5 & 3 & 1 & 29 & 4 & 5 & 2 & 1 & 1 & 3 & 1 \\
\hline 55 & 4 & $\mathrm{~N}$ & 4 & 4 & 5 & 4 & 1 & 30 & 4 & 5 & 2 & 5 & 5 & 3 & 1 \\
\hline 56 & 2 & 4 & 2 & 4 & 3 & 3 & 1 & 31 & 3 & 3 & 1 & 6 & 5 & 3 & 1 \\
\hline 57 & 4 & 1 & 2 & 4 & 3 & 3 & 1 & 32 & 4 & 5 & 2 & 3 & 1 & 2 & 1 \\
\hline 58 & 1 & 3 & 2 & 4 & 3 & 3 & 2 & 33 & 4 & $\mathrm{~N}$ & 2 & 5 & 5 & 2 & 1 \\
\hline 59 & 4 & 5 & 2 & 2 & 5 & 1 & 1 & 34 & 4 & $\mathrm{~N}$ & 2 & 2 & 3 & 3 & 2 \\
\hline 60 & 4 & $\mathrm{~N}$ & 2 & 1 & 5 & 3 & 1 & 35 & 4 & 5 & 2 & 6 & 3 & 3 & 1 \\
\hline 61 & 2 & 5 & 2 & 4 & 3 & 5 & 1 & 36 & 3 & 3 & 2 & 7 & 3 & 3 & 2 \\
\hline \multirow[t]{3}{*}{62} & 4 & 5 & 2 & 2 & 5 & 5 & 1 & 37 & 4 & 5 & 2 & 5 & 5 & 2 & 1 \\
\hline & & & & & & & & 38 & 3 & 3 & 4 & 5 & 3 & 3 & 1 \\
\hline & & & & & & & & 39 & 4 & 5 & 2 & 9 & 1 & 3 & 1 \\
\hline \multicolumn{4}{|c|}{ Sample set 3} & & & & & 40 & 3 & 3 & 2 & 3 & 3 & 3 & 1 \\
\hline 1 & 4 & 5 & 2 & 4 & 5 & 3 & 28 & 41 & 3 & 3 & 4 & 6 & 2 & 3 & 1 \\
\hline 2 & 3 & 3 & 2 & 5 & 3 & 3 & 2 & 42 & 3 & 2 & 2 & 4 & 5 & 3 & 1 \\
\hline 3 & 4 & 5 & 1 & 3 & 5 & 3 & 1 & 43 & 3 & 3 & 2 & 6 & 2 & 3 & 1 \\
\hline 4 & 4 & 5 & 2 & 5 & 3 & 3 & 2 & 44 & 4 & $\mathrm{~N}$ & 2 & 2 & 5 & 2 & 1 \\
\hline 5 & 4 & 5 & 2 & 3 & 5 & 3 & 3 & 45 & 3 & 3 & 4 & 6 & 3 & 3 & 1 \\
\hline 6 & 3 & 5 & 2 & 3 & 5 & 3 & 1 & 46 & 4 & $\mathrm{~N}$ & 2 & 3 & 5 & 1 & 1 \\
\hline 7 & 4 & 3 & 2 & 6 & 1 & 3 & 1 & 47 & 3 & 3 & 2 & 4 & 3 & 1 & 1 \\
\hline 8 & 3 & 3 & 2 & 6 & 3 & 3 & 2 & 48 & 3 & 3 & 2 & 3 & 5 & 3 & 1 \\
\hline 9 & 3 & 5 & 2 & 6 & 3 & 3 & 2 & 49 & 3 & 5 & 2 & 4 & 5 & 3 & 1 \\
\hline 10 & 2 & 3 & 2 & 7 & 3 & 1 & 1 & 50 & 3 & 5 & 2 & 4 & 3 & 3 & 1 \\
\hline 11 & 4 & 5 & 2 & $\mathrm{~N}$ & 5 & 3 & 2 & 51 & 3 & 6 & 2 & 2 & 5 & 3 & 1 \\
\hline 12 & 3 & 3 & 2 & 4 & 3 & 3 & 6 & 52 & 4 & $\mathrm{~N}$ & 2 & 4 & 5 & 3 & 1 \\
\hline 13 & 3 & 3 & 2 & 6 & 6 & 3 & 2 & 53 & 4 & $\mathrm{~N}$ & 2 & 5 & 5 & 3 & 1 \\
\hline 14 & 2 & 3 & 2 & 5 & 3 & 1 & 1 & 54 & 4 & $\mathrm{~N}$ & 2 & 4 & 3 & 3 & 1 \\
\hline 15 & 2 & 5 & 2 & 4 & 5 & 3 & 1 & 55 & 2 & $\mathrm{~N}$ & 2 & 4 & 3 & 1 & 1 \\
\hline
\end{tabular}

N, Null.

\section{Linkage disequilibrium and chromosomal map distance}

Comparisons of pairs of loci showed that highly significant linkage disequilibrium was occurring. Using the frequency of the major alleles versus that of the pooled remaining alleles at each locus, each pair of loci was tested for disequilibrium. The effect of chromosomal map distance on the estimated level of disequilibrium between pairs of loci was examined. There was no correlation between the intensity of disequilibrium and decreasing map distance.

Examination of haplotypes differing from the parental clone at two loci showed no association between the loci changed and the order of the loci on the chromosome. 
Table 4. Electromorph types of the four clones that constitute the 'parental' phenotypes for the clonal 'families' or quasi-species

\begin{tabular}{|lcccccc|}
\hline Family & GPI & ADH & GPD & PGD & IDH & PGM \\
\hline A & 2 & 3 & 2 & 4 & 3 & 3 \\
B & 4 & 5 & 2 & 4 & 5 & 3 \\
C & 4 & 5 & 2 & 6 & 3 & 1 \\
D & 3 & 3 & 2 & 6 & 3 & 3 \\
\hline
\end{tabular}

Table 5. Frequency of clones, and $G P D^{4}$ and $P G D^{4}$ alleles in each clone family, in the sample sets

Some clones could be allocated to more than one family. In such cases they have been included in all relevant categories, i.e. the total number of clones appears to be more than 100 . The final category 'unplaced' is for clones that do not fit any family.

\begin{tabular}{|lrrr|}
\hline & \multicolumn{3}{c|}{ Set } \\
\cline { 2 - 4 } & $\mathbf{1}$ & $\mathbf{2}$ & $\mathbf{3}$ \\
\hline Clones & & & \\
A & 61 & 62 & 23 \\
B & 23 & 17 & 46 \\
C & 12 & 7 & 4 \\
D & 29 & 32 & 33 \\
Unplaced & 12 & 11 & 11 \\
GPD & & & \\
A & 0 & 3 & 0 \\
B & 2 & 4 & 0 \\
C & 0 & 6 & 1 \\
D & 0 & 0 & 3 \\
PGD & & & \\
A & 26 & 40 & 9 \\
B & 12 & 14 & 3 \\
C & 3 & 6 & 2 \\
D & 3 & 2 & 8 \\
\hline
\end{tabular}

\section{DISCUSSION}

\section{Allelic variation}

All of the six enzyme loci studied were polymorphic, with the levels of variation being similar to that found in other studies (e.g. Selander et al., 1986). A rate-limiting enzyme (GPD) displayed the lowest level of polymorphism, while the enzyme loci coding for PGD, which is the following enzyme in the pentose phosphate shunt, displayed the greatest level of allelic variation. Clarke \& Allendorf (1979) suggested that regulatory (rate limiting) loci would display higher levels of variation than nonregulatory enzymes. The findings of this study do not support this prediction. Analysis of the kinetic characteristics of the alleles found in this study was the subject of a parallel study where large differences in characteristics were measured (B. J. Richardson \& G. M. Pupo, unpublished).

It is noteworthy that null alleles occurred in enzymes in subsidiary pathways (GPD, PGD, PGM and ADH) but not in GPI or IDH, which are enzymes fundamental to intermediary metabolism. The highest number of null alleles occurred for $\mathrm{ADH}$, probably the least essential enzyme studied. Dykhuizen \& Hartl (1980) reported that null alleles for PGD were consistently selected against in chemostat experiments, so it is surprising that such a high level $(3 \%)$ of null alleles was observed.

A large number of electromorphs were found to differ only at one enzyme locus. This suggests that most of them were derived recently from common ancestors through the process of recombination (Milkman \& Bridges, 1990) or, less likely, mutation.

Highly significant changes in allele frequencies were observed between the sample sets. Because the study period was less than a year it cannot be inferred that selection based on seasonal changes, perhaps in host diet, was responsible for the changes observed in allelic frequencies, as cyclical changes could not be detected. A study conducted over more than one year would provide more information on the effects of seasonal variation in allele frequency. The highly significant changes in allelic frequencies were due to changes in the common alleles from period to period in a background of rarer types. Rare alleles may have been lost at particular times due to unfavourable conditions, drift, or being missed by the sample size. The latter explanation seems very likely, given the large number of haplotypes observed only once. The changes in frequency of common alleles needs explanation.

\section{Haplotype variation}

It is noteworthy that, as well as a wide range of rare haplotypes, particular haplotypes and families of haplotypes occur at high and variable frequencies. Because of the large number of hosts involved, a fact distinguishing this study from others, it can be concluded that particular haplotypes are maintained in many individuals at the same time, and that dominant haplotypes may change simultaneously in many hosts within a period of a few weeks.

The results from this study clearly demonstrate that the multilocus allele combinations observed in natural populations of $E$. coli are not random combinations of alleles from a single gene pool. Selander et al. (1987) suggested that, theoretically, the level of linkage disequilibrium observed in E. coli could be maintained, even with high rates of recombination, by relatively intense selection for particular combinations of alleles at the different loci. The level of linkage disequilibrium found in this study was not simply due to tight linkage as selection remains an option. Recurrent selection has been invoked to explain the repeated isolation of identical or nearly identical strains from different individuals (Whittam et al., 1983). 


\section{The basis of genetic structure}

The evidenced clonality, linkage disequilibrium, effective population size and level of allelic variation establish a context in which a number of factors that may be responsible for maintaining these characteristics can be considered.

The simplest hypothesis to account for the multilocus structure in $E$. coli is that the observed disequilibria result from independent genetic drift at each locus combined with low rates of recombination. However, genetic drift cannot be used to account for the large changes in allele frequencies observed between sampling times. The estimated effective population size of $10^{10}$ is so large, especially when combined with the large number of hosts involved, that genetic drift independently at each locus is unlikely to be a governing factor causing the observed large changes in allele frequency.

The large number of different rare haplotypes is best explained by recombination. The non-random distribution of genotypes, and the presence of the common haplotypes in many hosts, imply that the rate of recombination is not high enough to overcome linkage disequilibrium. As a consequence, low but real recombination rates are a likely contributing factor in producing the observed suite of rare haplotypes, and natural populations of $E$. coli can be considered to consist of a mixture of more or less independent and common clonal lines in a background of all possible combinations.

In this context two possible explanations of the genetic structure remain. The occurrence of the same haplotypes within and between each sample set could be the result of selection on specific alleles at the studied loci. Alternatively, the structure could be due to environmental conditions favouring particular haplotypes. Hitchhiking can be used to explain the observed changes in allele frequencies between sampling periods with selection occurring at other points in the genome.

The idea that different haplotypes may be adapted to different hosts or different sites within hosts as suggested by Maynard Smith (1991) is attractive. If haplotypes are adapted to particular environments, then the combination of hitchhiking events and real but low levels of recombination would explain the observed distribution of genetic variability.

The alternatives of locus-specific selection and hitchhiking could be differentiated by showing parallel changes in the frequency of specific alleles in more than one haplotype family. However, the results are ambiguous, with such changes being found occasionally, though other patterns are more common. Consequently, selection at the loci studied cannot provide a general explanation of the results. The forces identified as maintaining the genetic structure of natural E. coli populations are low but real levels of recombination, and natural selection, most likely between haplotype families. It is clear, however, that strong selection does play a major role in changes in the population of E. coli.

The question remains, however, as to the geographical location of this selection. The sampling methods used and the insignificant differences in the measured characteristics of the sewage make it unlikely that the differences between sampling periods were due to selection during the short period for which the material was in the sewer, and changes within the host gut environment seem likely. Changes in $E$. coli in the gut have been ascribed to several different causes, most notably to changes in niches for gut flora (e.g. Reeves, 1992). The observed changes could have been due to changes in the diet of the host population, for example between summer and winter foods. Such changes could lead to a change in the size or nature of habitats in the host gut. It would be of great interest to ascertain whether the same clones increased and decreased in strength in the same seasons of different years and the effect of different ethnic host groups, with different dietary habits and cycles but living in the same city, on the distribution of clones.

\section{ACKNOWLEDGEMENTS}

We would like to thank R. Arumugasgwamy, C. Adkins, D. Mulry and $\mathrm{M}$. Jones for practical advice and support during this project. We would like also to thank our colleagues J. Markham, R. Yardin and N. Hristov for useful discussions throughout the project.

\section{REFERENCES}

Clarke, B. \& Allendorf, F. W. (1979). Frequency-dependent selection due to kinetic differences between allozymes. Nature 279, 732-734.

Caugant, D. A., Mocca, L. F., Frasch, C. E., Froholm, L. O., Zollinger, W. D. \& Selander, R. K. (1987). Genetic structure of Neisseria meningitidis populations in relation to serogroup, serotype, and outer membrane protein pattern. $J$ Bacteriol 169, 2781-2792.

Dykhuizen, D. E. \& Hartl, D. L. (1980). Selective neutrality of 6PGD allozymes in E. coli and the effects of genetic background. Genetics 96, 801-817.

Dykhuizen, D. E. \& Dean, A. M. (1990). Enzyme activity and fitness: Evolution in solution. Trends Ecol \& Evol 5, 257-262.

Eigen, M., McCaskill, J. \& Schuster, P. (1988). Molecular quasispecies. J Phys Chem 92, 6881-6891.

Helling, R. B., Vargas, C. N. \& Adams, J. (1987). Evolution of Escherichia coli during growth in a constant environment. Genetics 116, 349-358.

Levin, B. R. (1981). Periodic selection, infectious gene exchange and the genetic structure of Escherichia coli populations. Genetics 99 , $1-23$.

Maynard Smith, J. (1991). The population genetics of bacteria. Proc $R$ Soc Lond B 245, 37-41.

Milkman, R. (1972). How much room is there left for nonDarwinian evolution? In Evolution of Genetic Systems, pp. 217-229. Edited by H. H. Smith. New York: Gordon \& Breach.

Milkman, R. (1973). Electrophoretic variation in Escherichia coli from natural sources. Science 182, 1024-1026. 
Milkman, R. \& Bridges, M. Mck. (1990). Molecular evolution of the Escherichia coli chromosome. III. Clonal frames. Genetics 126, 505-517.

Nei, M. (1975). The cost of natural selection and the extent of enzyme polymorphism. Trends Biochem $S_{c i}$ 1, 247-248.

Nei, M. \& Grauer, D. (1984). Extent of protein polymorphism and the neutral mutation theory. Evol Biol 17, 73-118.

Reeves, P. R. (1992). Variation in O-antigens, niche-specific selection and bacterial populations. FEMS Microbiol Lett 100, 509-516.

Richardson, B. J., Baverstock, P. R. \& Adams, M. (1986). Allozyme Electrophoresis - a Handbook for Animal Systematics and Population Studies. Sydney: Academic Press.

Sawyer, S. A., Dykhuizen, D. E. \& Hartl, D. L. (1987). Confidence interval for the number of selectively neutral amino acid polymorphisms. Proc Natl Acad Sci US A 84, 6225-6228.

Selander, R. K. \& Levin, B. R. (1980). Genetic diversity and structure in Escherichia coli. Science 210, 545-547.
Selander, R. K. \& Musser, J. M. (1990). Population genetics of bacterial pathogenesis. In The Bacteria, vol. 11, pp. 11-36. Edited by B. H. Iglweski \& V. L. Clark. San Diego: Academic Press.

Selander, R. K., Korhonen, T. K., Vaisanen-Rhen, V., Williams, P. H., Pattison, P. E. \& Caugant, D. A. (1986). Genetic relationships and clonal structure of strains of Escherichia coli causing neonatal septicemia and meningitis. Infect Immun 52, 213-222.

Selander, R. K., Caugant, D. A. \& Whittam, T. S. (1987). Genetic structure and variation in natural populations of Escherichia coli. In Escherichia coli and Salmonella typhimurium: Cellular and Molecular Biology, pp. 1635-1648. Edited by F. C. Neidardt and others. Washington, DC: American Society for Microbiology.

Whittam, T. S., Ochman, H. \& Selander, R. K. (1983). Geographic components of linkage disequilibrium in natural populations of Escherichia coli. Mol Biol Evol 1, 67-83.

Received 23 May 1994; revised 14 November 1994; accepted 25 November 1994. 